\title{
A A national survey of clinical practice for the EDITOR'S CHOICE management of whiplash-associated disorders in UK emergency departments
}

\author{
S E Lamb, ${ }^{1}$ M A Williams, ${ }^{1}$ E Withers, ${ }^{1}$ J Perry, ${ }^{2}$ S Gates, ${ }^{1}$ E Williamson, ${ }^{1}$ \\ M Underwood, ${ }^{1}$ M Cooke ${ }^{1}$
}

\begin{abstract}
- Additional supplemental fig 1 is published online only at http:// emj.bmj.com/content/vol26/ issue 9

${ }^{1}$ University of Warwick, Coventry, UK; ${ }^{2}$ Coventry University, Coventry, UK

Correspondence to: Professor S E Lamb, Warwick Clinical Trials Unit, Medical School Building, Gibbet Hill Campus, University of Warwick, Coventry CV4 7AL, UK: s.lamb@warwick.ac.uk
\end{abstract}

Accepted 21 October 2008

\section{ABSTRACT}

Objective: To undertake a national survey to determine current practice for the management of whiplash injuries in UK emergency departments (ED).

Methods: Postal questionnaire survey. 316 lead consultants from all UK ED with annual new attendances of over 50000 people were asked to indicate the use of a range of treatments and the frequency with which these treatments were used. Samples of written advice were requested and content analysis was conducted and compared with survey responses.

Results: The response rate was 79\% (251/316). The intervention most frequently used was verbal advice to exercise, reported by $84 \%$ of respondents for most or all cases, and advice against the use of a collar (83\%). Other treatments reported as being used frequently were written advice and anti-inflammatory medication. 106 consultants (42\%) provided a sample of written materials. Reference to expected recovery and encouragement for early return to activities were included in less than $6 \%$. Nearly $50 \%$ of written materials contained information on how to use a soft collar and $61 \%$ contained information on solicitors and pursuing a personal injury claim. There were important differences between reported verbal behaviours and written advice.

Conclusion: Verbal advice is the primary method for managing whiplash injuries in ED and is usually supplemented by written advice. Within individual hospitals there is a lack of consistency between verbal and written advice. The promotion of personal injury claims is a common feature of written advice. Research is required to develop effective and consistent models of advice.

Whiplash is a mechanism of injury as a result of acceleration-deceleration forces being applied to the neck, most commonly as a result of motor vehicle collision. The resulting signs and symptoms have been defined as whiplash-associated disorders (WAD). ${ }^{1}$

The majority of individuals who attend emergency departments (ED) following a whiplash injury will make a good recovery; however, a substantial minority (approximately 30\%) will continue to have problems and generate the majority of the costs. ${ }^{2}$ Although whiplash injuries are common, there are few robust randomised trials to inform practice. ${ }^{13}$ Spitzer et a ${ }^{1}$ in 1995 concluded that there was insufficient evidence to support the use of treatments currently used; however, the provision of consistent advice to resume normal activities in the early stages and not use a soft collar was probably the most effective way forward.

A 2007 Cochrane review of the literature regarding conservative treatments for whiplash reported that the evidence supporting advice to remain active and the effectiveness of various treatments, including mobilisation, manipulation and exercise, remains inconclusive, mostly as a result mostly of poor trial quality. ${ }^{3}$

The authors of a 2002 review $^{4}$ suggested that psychological risk factors predominate as risk factors for poor outcome (although more recent reviews have concluded that both physical and psychosocial factors are equally important). ${ }^{56}$ The review identified seven key messages shown in box 1. These were used to develop "The whiplash book"?

Indications that recovery from WAD may be influenced by compensation and legal factors arise from a surprisingly limited number of sources. In 2007 a systematic review of prognostic factors in $\mathrm{WAD}^{8}$ could only find two appropriate studies. Only one of the studies addressed this issue. It found change from a tort to no-fault compensation system resulted in a significant reduction in timeto-claim closure. ${ }^{9}$ These findings have been viewed with caution on the basis of limited study methodology and studies that show that pain does not necessarily resolve once litigation is concluded. ${ }^{10}$

Our overall aim was to undertake a national survey to determine current practice for the management of acute WAD in UK ED. In addition, we sought to undertake a quality appraisal of written information provided to patients and compare reported clinical behaviours with written information provided.

\section{METHODS}

We identified all $316 \mathrm{ED}$ in the UK seeing more than 50000 new patients per year from the British Association of Accident and Emergency Medicine Directory 2002/3. We sent the lead consultants a brief questionnaire (see supplemental fig 1 available online only) that asked "On how many acute neck sprain cases are the following treatments used in your department?" Responses were categorised as no cases, rarely $(<10 \%)$, selected cases, most cases $(>90 \%)$ or all cases. Responses were elicited for a range of treatments; rest, soft collars, verbal advice to use ice, heat or exercise, written advice, drug treatments, investigations, referral to psychological and physical therapies and methods of 
Box 1 Key messages from McClune and colleagues ${ }^{4}$ (2002)

- Serious physical injury is rare.

- Positive attitudes to prognosis and recovery are important.

- Early return to normal pre-accident activity and occupation is important.

- Self-management with pain control minimises chronicity.

- Collars and rest can delay recovery.

- Exercise enhances recovery.

- Negative attitudes delay recovery and contribute to chronicity.

follow-up. Consultants were asked to provide details of referral criteria for physiotherapy and other treatments that they regularly referred to. In addition, consultants were requested to supply a copy of any written advice used by the department.

We posted the questionnaires, consisting of one side of A4 paper, with a cover letter explaining the purpose of the survey. We telephoned non-responders to ensure that their details were correct and sent a second copy of the questionnaire. We received replies by fax or by pre-paid reply envelope. The first mailing of questionnaires took place in June 2003, with reminders sent out in September 2003.

\section{Data analysis}

Questionnaire data were summarised as frequency counts for each question, and are presented as one of three response options: (1) no or rare (<10\%) cases; (2) selected cases; (3) most $(>90 \%)$ or all cases (see table 1). Further analysis determined whether departments were using multiple modes of treatment and whether in some categories they reported no activity at all. In all cases we are reporting the respondents' perception of what happens in their department. We are not able to comment directly on the respondents' actual practice or that of other members of their department. Statistical analyses were conducted using SpSS version 15.

For the written information evaluation, two approaches were used. All samples of written material were assessed for the presence of the seven key messages identified by McClune et $\mathrm{al}^{4}$ (box 1). Before full content analysis, the samples were reviewed to determine whether there were any additional themes recurring in the advice. Three were discovered and added to the content analysis schedule-sleeping, posture and pursuing a personal injury claim. Two researchers undertook the content analysis independently. Situations of disagreement were resolved by consensus. For those departments who used written materials and provided an example, comparisons were drawn between reported clinical activity on the questionnaire and the written material in three areas of advice to: (1) rest; (2) exercise and (3) use soft collars.

\section{RESULTS}

\section{Questionnaire results}

The response rate to the questionnaire was $79 \%$ (251/316 questionnaires; table 1).

\section{Treatments used in most or all cases}

The treatments most frequently used for most or all cases were verbal advice to exercise 210/251 (84\%), advice against the use of a soft collar 209/251 (83\%), written advice designed by the department 176/251 (70\%) and oral non-steroidal anti-inflammatory drugs (NSAID) 162/251 (65\%). The majority used more than one of these approaches; by far the most frequent combination was verbal advice to exercise combined with advice not to use a soft collar 181/251 (72\%).

\section{Treatments used in selected cases}

Radiological investigations, physiotherapy and analgesics other than NSAID were used most often for selected cases $(61 \%, 60 \%$ and $41 \%$, respectively). Case selection criteria were greater pain and more severe symptoms at initial presentation and those who did not improve.

\section{Soft collars}

The modal protocol for the use of soft collars for selected cases was short-term use ( $<3$ days) 16/251 (6\% of sample); two of $251(0.8 \%)$ recommended the use of a collar for most or all cases for at least one week.

\section{Rest}

Nearly two-thirds 160/251 (64\%) specifically advised against rest for most or all cases, but for $2 \%$ of consultants the opposite was the case; that is they advised rest for longer than one week in most or all cases. When rest was advised, the majority of consultants advocated three or fewer rest days (38/251; 15\%).

\section{Written advice}

Of the departments providing written advice to patients, the most common format was material specific to the department (supplied by 176/251 (70\%) of departments to most or all cases). Only 10/251 (4\%) used "The whiplash book" for most or all cases and the remainder used other formats.

\section{Analgesia}

Only two consultants stated they did not recommend oral analgesia. The commonest form of analgesia recommend was oral NSAID. Nearly equal numbers of consultants prescribed oral NSAID tablets in isolation (33\%), or given in combination with another analgesic (38\%).

\section{Follow-up}

Nearly all departments recommended follow-up of some kind, with general practice being the most common form of recommended follow-up for most or all cases (107/251; 43\%). ED or outpatient follow-up was limited to selected cases.

\section{Treatments rarely or never used}

These included nerve blocks, injections, "The whiplash book", psychologist, counselling and topical NSAID. The application of heat and cold was advised by less than $50 \%$ of the sample and then only for selected cases.

\section{Appraisal of written advice}

We received samples of written advice from 106 departments, representing $34 \%$ of the consultants sampled and $50 \%$ of the consultants who reported that they used advice materials. Consultants who used "The whiplash book" were less likely to provide a sample. There were no other differences in the clinical management profile between those who did or did not provide a sample. Table 2 displays a summary of the content analysis.

The messages most frequently conveyed by the advice sheets related to analgesia, exercise and sleeping positions. Most (65/ 106; 61\%) advice sheets contained a solicitor's advert or more explicit instructions on how to pursue a personal injury claim. 
Table 1 Responses to questionnaire items

\begin{tabular}{|c|c|c|c|c|}
\hline \multirow[b]{2}{*}{ Questionnaire item } & \multicolumn{4}{|l|}{$(n=251)$} \\
\hline & $\begin{array}{l}\text { No or rare } \\
\text { cases } \\
\text { n }(\%)\end{array}$ & $\begin{array}{l}\text { Selected } \\
\text { cases } \\
\text { n (\%) }\end{array}$ & $\begin{array}{l}\text { Most or all } \\
\text { cases } \\
\text { n (\%) }\end{array}$ & $\begin{array}{l}\text { No response } \\
\text { n (\%) }\end{array}$ \\
\hline \multicolumn{5}{|l|}{ Rest } \\
\hline Patients advised against rest & $35(14)$ & $27(11)$ & $160(64)$ & $29(12)$ \\
\hline Rest for $<3$ days & $51(20)$ & $31(12)$ & $38(15)$ & $131(52)$ \\
\hline Rest for $4-7$ days & $77(31)$ & $15(6)$ & $9(4)$ & $150(60)$ \\
\hline Rest for $>1$ week & $84(33)$ & $10(4)$ & $4(2)$ & $153(61)$ \\
\hline \multicolumn{5}{|l|}{ Soft collar } \\
\hline Advised not to use collar & $19(8)$ & $7(3)$ & $209(83)$ & $16(6)$ \\
\hline Use for $<3$ days & $66(26)$ & $16(6)$ & $12(5)$ & $157(63)$ \\
\hline Use for 4-7 days & $73(29)$ & $7(3)$ & $8(3)$ & $163(65)$ \\
\hline Use for $>1$ week & $76(30)$ & $1(0)$ & $2(1)$ & $172(69)$ \\
\hline \multicolumn{5}{|l|}{ Verbal advice } \\
\hline Use ice & $98(39)$ & $35(14)$ & $38(15)$ & $80(32)$ \\
\hline Use heat & $78(31)$ & $42(17)$ & $51(20)$ & $80(32)$ \\
\hline Do neck exercises & $8(3)$ & $20(8)$ & $210(84)$ & $13(5)$ \\
\hline \multicolumn{5}{|l|}{ Written advice } \\
\hline Designed by department & $28(11)$ & $10(4)$ & $176(70)$ & $37(15)$ \\
\hline The whiplash book & $102(41)$ & $2(1)$ & $10(4)$ & $137(55)$ \\
\hline Other & $84(33)$ & $2(1)$ & $18(7)$ & $147(59)$ \\
\hline \multicolumn{5}{|l|}{ Drug treatments advised/prescribed } \\
\hline NSAID tablets & $6(2)$ & $75(30)$ & $162(65)$ & $8(3)$ \\
\hline NSAID gel & $129(51)$ & $22(9)$ & $11(4)$ & $89(35)$ \\
\hline Other analgesic tablets & $19(8)$ & $104(41)$ & $83(33)$ & $45(18)$ \\
\hline Nerve blocks/injections & $169(67)$ & $0(0)$ & $1(0)$ & $81(32)$ \\
\hline Sedatives or muscle relaxants & $155(62)$ & $26(10)$ & $3(1)$ & $67(27)$ \\
\hline \multicolumn{5}{|l|}{ Investigations to guide early intervention } \\
\hline$x$ Rays & $67(27)$ & $153(61)$ & $23(9)$ & $8(3)$ \\
\hline MRI & $184(73)$ & $20(8)$ & $2(1)$ & $45(18)$ \\
\hline Refer to psychological/counselling services & $218(87)$ & $11(4)$ & $1(0)$ & $21(8)$ \\
\hline Use of physiotherapy & $71(28)$ & $151(60)$ & $20(8)$ & $9(4)$ \\
\hline \multicolumn{5}{|l|}{ Follow-up } \\
\hline ED clinic & $118(47)$ & $76(30)$ & $8(3)$ & $49(20)$ \\
\hline Other hospital clinic & $142(57)$ & $16(6)$ & $1(0)$ & $92(37)$ \\
\hline General practice & $44(18)$ & $64(25)$ & $107(43)$ & $36(14)$ \\
\hline Physiotherapy & $70(28)$ & $122(49)$ & $18(7)$ & $41(16)$ \\
\hline
\end{tabular}

Reassurances about longer-term recovery, the benefits of early return to work/normal activity and about the appropriate use of collars were rare (six of $106 ; 6 \%$ ).

In the subset of respondents who returned written information, there was a substantial mismatch between the reported clinical approach and the content of the advice sheets. Of the 94 consultants who reported that their department did not use a collar, 44 (47\%) provided explicit advice in the information sheet about how to use a collar. Only $17(16 \%)$ departments provided a consistent written statement that a collar should not be used. Six departments, who reported that they always used a collar in some manner, provided written advice against the use of collars.

Table 2 Summary of content analysis of written materials provided in the UK emergency department survey

\begin{tabular}{lccrr}
\hline & \multicolumn{3}{l}{$\begin{array}{l}\text { Present in written material provided } \\
\text { (n= 106) }\end{array}$} & \\
\cline { 2 - 5 } Theme & No & $\%$ & Yes & $\%$ \\
\hline Reassurance that serious injury is rare & 100 & 94 & 6 & 6 \\
Reassurance about early recovery & 66 & 62 & 40 & 38 \\
Advice about early return to activity and work & 101 & 95 & 5 & 5 \\
Advice on pain control and medication & 22 & 21 & 84 & 79 \\
Advice on exercises & 23 & 22 & 83 & 78 \\
Advice that a collar should not be used & 89 & 84 & 17 & 16 \\
Reassurance to minimise psychological symptoms & 101 & 95 & 5 & 5 \\
Advice on posture & 67 & 63 & 39 & 37 \\
Advice on sleeping & 17 & 16 & 89 & 84 \\
Solicitors advert included & 41 & 39 & 65 & 61 \\
\hline
\end{tabular}


With respect to exercise, $86 \%$ of departments who reported providing verbal advice to exercise did not provide information on exercises in their written advice. Written advice on exercise was often provided when verbal advice was not (82\%). Of the consultants who reported that they advised against rest, only $7 \%$ had written information that re-enforced this message.

In summary, nearly $38 \%$ of examples provided conflicting written and verbal advice, and an additional 34\% contained no reinforcement of key verbal messages. This was notable particularly in relation to collars.

\section{DISCUSSION}

Usual care in UK ED appears to constitute verbal advice to exercise the neck, which is supplemented in most cases by verbal advice not to use a collar. Most but not all departments supplement the consultation with written information. Other findings of our study are that: (1) patients are often given inconsistent verbal and written messages regarding important components of care, including the use of collars; (2) essential aspects of the clinical consultation, relating to messages about activity, avoiding collars and exercises are not reinforced in the written material; (3) a substantial proportion of advice leaflets are sponsored by personal injury claim solicitors, or encourage patients explicitly to pursue a personal injury claim; (4) the possibility exists that the use of collars is still routine in some departments.

The findings need to be treated with some caution as the study is based on the opinion of lead clinicians, not on actual practice. They are also based on the practice of larger departments; smaller departments may have less access to facilities and resources, for example, physiotherapy and magnetic resonance imaging. The variation in practice among clinicians within each department is unknown. We had a high response rate but non-responders may be atypical. We did not chase up consultants who did not send examples of their written material; this was optional to ensure we had a good response to the questionnaire. Reassuringly, there was no evidence of response bias at this level of the study. Although we have a large sample, the questionnaire was brief with limited response options. Simple, short questionnaires are often the key to a good response rate. ${ }^{11}$ The study examines practice in ED only. Patients presenting to ED may be subtly or substantially different to those presenting to primary care or other settings, and may well be treated with a different emphasis.

Our survey is consistent with another survey conducted in $2001 / 2,{ }^{12}$ in which $50 \%$ of consultants in Wales reported using collars. McClune et $a l^{4}$ also performed a survey of 110 UK NHS ED in 2000/1 but only received 29 examples of advice materials. Sixty per cent $(18 / 29)$ were commercially produced cards with the name and contact details of a solicitor, very similar to the findings in this survey.
The highly visible presence of solicitors and the ability to pursue personal injury claims in the written materials raises the question of whether litigation may facilitate inappropriate illness behaviour in this population. The evidence is uncertain at present and certainly requires further carefully conducted investigation.

\section{CONCLUSION}

Verbal advice is the primary method for managing whiplash injuries in ED and is usually supplemented by written advice. Within individual hospitals there is a marked lack of consistency between verbal and written advice. The promotion of personal injury claims is a common feature of written advice-at present it is not certain whether this may hinder recovery. Research is required to develop effective and consistent models of advice; the preferred method would be a randomised controlled trial comparing different advice models.

Acknowledgements: The authors would like to extend many thanks to the clinicians who responded to the survey.

Funding: Financial support for this work was provided as part of funding for the Managing Injuries of the Neck Trial by the NIHR Health Technology Assessment Programme (ISRCTN33302125).

Competing interests: None.

Ethics approval: The study had ethical approval.

\section{REFERENCES}

1. Spitzer W, Skovron M, Salmi L, et al. Scientific monograph of the Quebec Task Force on Whiplash-Associated Disorders: redefining "whiplash" and its management. Spine 1995;20(8 Suppl):1-73S.

2. Galasko CSB. The cost of whiplash-associated disorders. In: Gunzberg R, Szpalski $\mathrm{M}$, eds. Whiplash injuries: current concepts in prevention, diagnosis, and treatment of the cervical whiplash syndrome. Philadelphia: Lippincott-Raven, 1998:283-90.

3. Verhagen A, Scholten-Peeters G, van Wijngaarden S, et al. Conservative treatments for whiplash. Cochrane Database Syst Rev 2007;(2):CD003338.

4. McClune T, Burton AK, Waddell G. Whiplash associated disorders: a review of the literature to guide patient information and advice. Emerg Med J 2002;19:499-506.

5. Williams M, Williamson E, Gates S, et al. A systematic literature review of physical factors and the development of late whiplash syndrome. Spine 2007;32:E764-80.

6. Williamson $\mathbf{E}$, Williams $M$, Gates $S$, et al. A systematic literature review of psychological factors and the development of late whiplash syndrome. Pain 2008;135:20-30.

7. Burton K, Tim M, Gordon W. The whiplash book. London: TSO, 2005.

8. Carroll L, Holm L, Hogg-Johnson S, et al. Course and prognostic factors for neck pain in whiplash-associated disorders (WAD): results of the Bone and Joint Decade 20002010 Task Force on Neck Pain and Its Associated Disorders. Spine 2008;33/4 Suppl):S83-92.

9. Cassidy JD, Carroll LJ, Cote P, et al. Effect of eliminating compensation for pain and suffering on the outcome of insurance claims for whiplash injury. N Engl J Med 2000;342:1179-86.

10. Pennie B, Agambar L. Patterns of injury and recovery in whiplash. Injury 1991;22:57-9.

11. Edwards $\mathbf{P}$, Roberts I, Clarke M, et al. Methods to increase response rates to postal questionnaires. Cochrane Database Syst Rev 2007;(2):MR00000.

12. Logan AJ, Holt MD. Management of whiplash injuries presenting to accident and emergency departments in Wales. Emerg Med J 2003;20:354-5. 